This Report was, unfortunately, shelved by reason of minor errors in the statistical figures, though it was admitted by the Association that these errors in no way altered the real value of the document. The Report was published, and can no doubt be obtained from the secretary of the Medico-Psychoogical Association.

Practically very little has been done, and the death-rate of tuberculosis in asylums is still increasing. The Board of Control recognise this fact, but simply make recommendations and insist on nothing. If they have no power under the Lunacy Act of 1890 to enforce their recommendations, why do not they obtain that power or urge the Ministry of Health to obtain it for them? I have pointed all this out in a recent book of mine. Something more must be done. A Ministry of Health is about to open a campaign for the physical improvement of the nation. To my mind the whole question of the death-rate of tuberculosis in our large asylums is a standing disgrace to our country, and I earnestly hope something will soon be done to mitigate this crying evil. I am, Sir, yours faithfully,

Bournemouth, Sept. 1st, 1919. L. A. WEATHERLY, M.D.

\section{INJECTIONS OF TARTAR EMETIC IN BILHARZIASIS.}

To the Editor of THE LANCET.

SrR, - In a paper on this subject published in your issue of August 9th Dr. Frank E. Taylor draws attention to the risk of antimony poisoning as the results of intravenous injections. He goes on to say that the toxicity of arsenic has been greatly reduced by introducing it in organic combination, and that it would appear highly probable that similar organic compounds of antimony could be produced combining equal therapeutic effects with diminished toxicity. As no further allusion to any such substance was made either by Dr. Taylor or by Dr. J. B. Christopherson in his letter on the same subject in the following issue, it may interest your readers to know that Dr. G. Caronia, editor of La Pediatria, has experimented as far back as 1916 with preparations of antimony as injections in external kala-azar and leishmaniasis. He gave the preference to acetyl-paminophenyl, stibiate of sodium, on account of its greater efficacy, easy absorption, and less toxicity. It is freely soluble in distilled water and contains 38.5 per cent. of antimony, and may be given in doses up to $20 \mathrm{cg}$. I am, Sir, yours faithfully,

T. VINCEnT DiCKinson.

Cadogan Mansions, S.W., Sept. 2nd, 1919.

\section{EARLY MENTAL HOMES.}

To the Editor of THE LANCET.

Srr, - It was recently stated, in answer to a question in the House of Commons, that the provision of convalescent homes for early uncertifiable mental cases (without detention and on a purely hospital basis) would come under the province of the new health authority. It is admitted that such homes would be a great bcon in intercepting cases (especially those occurring among ex-soldiers) who would otherwise be relegated to asylums. The Lunacy Board, according to its annual reports, has long desired the institution of "reception houses" under its wing where early cases could be detained, say for six months, without certificationi.e., without any judicial investigation or appeal. A Bill with this object, entitled the "Mental Treatment Bill" was introduced by the Home Office in 1915, but had to be withdrawn, the House of Commons regarding it as an annulling of the safeguards of the Lunacy Act and an infringement of the rights of the individual. From recent indications it appears that a similar Bill is now again in contemplation. The Lunacy Board has, however, no juris diction over uncertified and uncertifiable persons; and in order that cases in the very early and most curable stages should be induced to enter these homes voluntarily (as they would enter a hospital), it is essential that the homes should have no connexion with lunacy, else they will be regarded as "half-way-houses" to asylums, and shunned by the very people for whom they are intended. Public money, if sunk in such homes, will be for the most part entirely wasted.

It is a mistake to think that legislation is needed for the provision of sanatoria which do not involve detention. The Public Health Act, 1875, has already conferred on borough councils the power to run hospitals, and similar powers could be readily extended to the London County Council and county councils generally. The cheering and hopeful atmosphere produced by the fact that the terms, both of admission and of stay, are voluntary, is in itself a most important factor in recovery. It is not the existence of legal safeguards which creates "stigma," but the fact of being subjected to detention. It is in the interest of the public that every case in which restraint is applied should be carefully investigated under judicial procedure, and the salutary provision contained in Section 315 of the Lunacy Act ought to be strengthened and not annulled. On the other hand, every case proved to be "dangerous and unfit to be at large," ought to be certified, and no trivial and uncertifiable case ought to be subjected by any underhand method to detention.

I am, Sir, yours faithfully,

S. E. White, M.B., B.Sc.

Upper Montagu-street, W., August 21st, 1919.

\section{THE FTIOLOGY OF INFLUENZA.}

\section{To the Editor of THE LANCET.}

SIR,-Captain G. E. Beaumont in his paper on this subject in THE LANCET of August 9th records that examination of material from influenza patients has shown the presence of a "mycotic organism." I do not wish to comment on his results beyond saying that there must be rigid proof before one can accept "hyphæ, large spores, coccal clusters, small spores, tetrads, mulberry masses, chains of cocci, bacilli" as pleomorphs of the same organism. My object in writing is to point out how inadequate from the point of view of a systematist are the figures of fungi usually appearing in medical literature. In the present instance it is impossible from the diagram to hazard a guess as to the fungal genus in which the hyphal stage of the organism would normally be placed. The manner in which the spores are borne is the important point in classification, and this should be clearly shown in any figures. This can rarely be made out in film preparations, but is best studied by mounting the fungus in absolute alcohol; the preparation may be made more permanent by running in dilute glycerine and "ringing" after a week or so. I am, Sir, yours faithfully,

British Museum (Natural History), August 26th, 1919. J. RAMSBOTTOM.

\section{THE RESULTS OF COMPLETE COLECTOMY.}

To the Editor of THE LANCET.

SIR,-In your issue of August 9th there is a letter from Mr. J. F. Dobson, of Leeds, in reference to a paper of mine on colectomy, in which he says that the operation of complete colectomy will remain under a cloud as long as those surgeons who perform it are content to support their views by the publication of their cases in an imperfect manner. Mr. Dobson's criticism is, up to a certain point, merited, in that very few details of the after-histories of my cases were appended, but the implication that discredit must, as a consequence, fall upon the operation because such histories were unknown or unfavourable, cannot pass without comment. At the time of writing I was perfectly well aware that the condition of the patients to whom I referred was satisfactory, but I had not sufficient recent detail to make it worth while to do more than indicate in a general way that the results of the operation were good. Perhaps I took for granted in my realisation of this fact that critics would accept it as a matter of course. Since Mr. Dobson's letter appeared I have communicated with my patients again, and I hope that he will agree that the details supplied now bear out the general statement made in the paper.

Mr. Dobson mentions specially the after-progress of Cases 1 and 2. In a letter I have just received from Case 1 are these remarks: "I am in good general health; I get no pain after eating, as before the operation. I believe the operation to be a great success." He goes on to say that he is employed in one of the shipping lines in Liverpool. Nearly two years have elapsed since I operated on him. Case 2 writes that he was playing football ten-weeks after the operation, and that he has had no trouble with his bowels, although they move three times a day. This colectomy was done six months ago. Mr. Dobson finally deplores the absence of " a full description of the diseased condition of 